\title{
DIREITO E FRATERNIDADE: A DIGNIDADE HUMANA COMO FUNDAMENTO
}

\section{LAW AND FRATERNITY: HUMAN DIGNITY AS A FOUNDATION Eligio Resta ${ }^{1}$ \\ Clara Cardoso Machado Jaborandy² Sandra Regina Martini ${ }^{3}$}

\begin{abstract}
Recebido em: 22/11/2017 Aceito em: 29/12/2017

srmvial@terra.com.br
\end{abstract}

Resumo: O presente trabalho pretende realizar uma revisão bibliográfica sobre o tratamento jurídico da dignidade da pessoa humana com o intuito de verificar a conexão com a fraternidade. Para tanto, discorre inicialmente sobre a trajetória normativa da dignidade, demonstrando que a nova centralidade do conceito de dignidade está diretamente relacionada a fatores de unificação cultural como os direitos humanos e a fraternidade. Posteriormente, aborda a compreensão jurídica da dignidade e sua relação com a fraternidade, retratando o liame existente entre os dois conceitos e a necessidade de observância de ambos para a plena efetivação de seus conteúdos normativos. Como metodologia aplicada à pesquisa, utilizou-se, inicialmente, o método indutivo, alcançando a premissa geral na trajetória normativa da dignidade, para posteriormente utilizar o método dedutivo e descritivo e assim verificar a conexão da dignidade com a fraternidade. Quanto aos procedimentos, foram utilizadas as técnicas provenientes dos tipos de pesquisas bibliográfica e documental.

Palavras-chave: Direito Fraterno. Dignidade. Fraternidade.

\begin{abstract}
The present work intends to carry out a bibliographical revision on the juridical treatment of the human dignity in order to verify the connection with the fraternity. Therefore, it initially explores the normative trajectory of dignity, demonstrating that the new centrality of the concept of dignity is directly related to factors of cultural unification such as human rights and fraternity. Later, it approaches the juridical comprehension of dignity and its relation with the fraternity, portraying the existing relationship between the two concepts and the need of observance of both for the full effectiveness of its normative contents. As a methodology applied to research, the inductive method was initially used, reaching the general premise in the normative trajectory of dignity, to later use the deductive and descriptive method and thus to verify the connection of dignity with fraternity. As for the procedures, the techniques from the types of bibliographic and documentary research were used.
\end{abstract}

Keywords: Fraternal Right. Dignity. Fraternity.

\section{INTRODUÇÃO}

Iniciamos fazendo uma breve contextualização sobre o estudo do Direito Fraterno. Embora tenha sido deixada de lado durante muitos séculos, a fraternidade reaparece no cenário mundial e retorna para ficar e desacomodar os pressupostos tradicionais que se propunham a dar certezas, especialmente no direito. O Direito Fraterno toma forma no Brasil na década de 90, quando Eligio Resta inicia suas discussões sobre o esquecimento da fraternidade na Europa, com maior impacto na

\footnotetext{
${ }^{1}$ Universidade de Roma TRE - Itália

${ }^{2}$ Universidade Tiradentes - Brasil

${ }^{3}$ Centro Universitário Ritter dos Reis - UniRitter - Brasil
} 
Itália ${ }^{4}$. Foram vários seminários, palestras, orientações de doutorado, até que em 2002 surge o livro "Il diritto fraterno" publicado pela Editora Laterza e traduzido no Brasil pela editora EDUNISC.

A "novidade teórica", mais uma vez abalou o mundo da sociologia jurídica, causando estranheza. A primeira conferência no Brasil sobre o tema foi em 1997 durante seminários realizados em Porto Alegre, Santa Maria e Florianópolis, quando Resta trouxe o tema para debate. Porém, mais uma vez a fraternidade fica adormecida até 2003 quando, novamente Eligio Resta vem para Santa Cruz do Sul, a convite da UNISC, e alem do ciclo de conferências, debates, rodas de conversas com alunos da graduação e pós-graduação decide-se traduzir o livro "il diritto fraterno". Desde então, o tema da fraternidade tomou forma no Brasil e vários professores brasileiros fizeram pós doutoramento com Eligio Resta, vários grupos de estudiosos brasileiros e latino-americanos passaram a freqüentar a Universidade de Roma TRE para aprofundar o assunto ${ }^{5}$.

Outros estudos sobre fraternidade e direito já vinham sendo desenvolvidos, também na Itália no Instituto Sophia, com Antônio Maria Baggio, na Espanha com Angel Puyol "El derecho a la fraternidade" e em Portugal com Paulo Ferreira da Cunha, que neste ano lançou seu último livro sobre o tema "Direito Fraterno Humanista".

O tema deste artigo não é defender uma ou outra corrente, mas discutir a vinculação entre fraternidade e dignidade e seus impactos no direito atual. As breves palavras introdutórias foram necessárias para demarcar a importância da UNISC no contexto de pioneirismo para o desenvolvimento da teoria.

Após a segunda guerra mundial a dignidade humana passou a integrar, praticamente, todas as Constituições nacionais. Em pesquisa realizada no site "Constitute Project" constatou-se que das 194 Constituições que estão em vigor, 149 trazem a expressão "human dignity"6. Este dado não é por acaso, precisamos recordá-lo especialmente neste período histórico da humanidade, em que presenciamos muito mais indignidades do que dignidade.

Apesar da constitucionalização da dignidade (o que não é diferente da fraternidade), há ainda um grande déficit de efetividade na sua tutela da dignidade humana, fato que pode ter relação com a ausência de fraternidade. Estes conceitos estão interligados, pois se efetivamos a dignidade teremos fraternidade, se somos fraternos concretizamos a dignidade; o que não significa que sejam sinônimos, mas que estão conectados.

Por conseguinte, este artigo tem por escopo, como já afirmamos, verificar a conexão da dignidade humana com a fraternidade para compreender se a observância do princípio da fraternidade amplia a proteção da dignidade.

\footnotetext{
${ }^{4}$ As primeiras publicações sobre o direito fraterno começam em $1991 \mathrm{com}$ a publicação II diritto fraterno, Rel.Congresso A.I.S., in Sociologia del diritto, 3, 1991, 5, seguindo-se das publicações II diritto fraterno, in Disuguaglianze ed equità in Europa, a cura di L.Gallino, Laterza, Roma-Bari, 1993; El derecho fraterno, in Anales de la Catedra Francisco Suarez, 1994; La comunidad inconfesable y el derecho fraterno, in Identidades comunitaria y democrazia, a cura di H. S. Gorski, Trotta, Madrid, 2000.

${ }^{5}$ Nos anos de 2007 a 2009 Eligio Resta integrou o projeto de pesquisa "Direito, política e constituição: A argumentação jurídica de fundamentação das decisões judiciais e o respeito às garantias constitucionais do acusado no processo penal de emergência brasileiro" coordenado pelo Dr. Marcelo Andrade Cattoni de Oliveira e que tinha como integrantes Flaviane de Magalhães Barros Bolzan de Morais e Giacomo Marramao. Além disso foi coorientador da tese de doutorado de João Porto Silvério Júnior (2013), dentre outros trabalhos.

${ }^{6}$ Disponível em https://www.constituteproject.org/search?lang=en\&key=dignity
} 
Como metodologia aplicada à pesquisa, utilizou-se, inicialmente, o método indutivo, uma vez que entre as perspectivas de trabalho foram utilizadas: a observação do processo de trajetória jurídica da dignidade humana, a investigação das diferentes formas de compreensão da dignidade, bem como as suas dimensões. Posteriormente, após o encontro da premissa geral, possibilitada pelo método anteriormente descrito, se utilizou o método dedutivo e descritivo, uma vez que o raciocínio parte de uma premissa geral e volta-se para uma situação particular, qual seja, verificar a conexão com a fraternidade e se a ausência de fraternidade repercute na eficácia da dignidade humana.

Quanto aos procedimentos, foram utilizadas as técnicas provenientes dos tipos de pesquisas bibliográfica e documental, visto que foram utilizadas as técnicas de revisão e fichamento bibliográfico/documental.

\section{A TRAJETÓRIA NORMATIVA DA DIGNIDADE HUMANA}

A dignidade ingressa no universo normativo com uma longa história no campo semântico. Da filosofia antiga à contemporânea, da épica à ética, da política à religião não existe reflexão que, mesmo indiretamente, deixe de fazer referência à dignidade. Por ter se tornado a grande narrativa das Constituições, Declarações e Convenções Internacionais, a dignidade humana é um tema difícil para reflexão sobre o qual convergem inúmeros fatores histórico culturais. Observamos também, ao longo do processo histórico vários usos inadequados e não efetivados da dignidade, por isso, o tema precisa ser constantemente retomado, neste novo século, assim como no século anterior vivemos a banalização de semânticas como dignidade, fraternidade, hospitalidade, solidariedade.

Pode-se afirmar que a nova centralidade do conceito de dignidade, a partir da segunda metade do século passado, está diretamente relacionada a outros fatores de unificação cultural, que são a humanidade, os direitos humanos e, não menos importante, a fraternidade.

É evidente que entre a dignidade e a ideia de comunidade humana existe um nexo causal inseparável, descrito pelos grandes textos normativos que surgem logo após a II Guerra Mundial. E nos dias atuais, onde temos uma sociedade de mundo, não raras vezes nos esquecemos da importância da comunidade como um lugar onde me reconheço e sou reconhecido, um lugar onde a humanidade do homem pode se apresentar, assim como pode desvelar a dês-humanidade do próprio homem. É na comunidade que podemos regatar os velhos conceitos esquecidos, é através da comunidade que podemos nos conectar com o mundo, é na comunidade que encontramos o sentido da auto- responsabilização pelo "outro".

A dignidade também é espelho de uma auto-observação da comunidade humana como um todo e, não somente na comunidade nacional. Nesta comunidade se observa também a passagem fundamental de cidadão à pessoa humana e à sua comunidade de referência. Para testemunhar essa narrativa, destinada a substituir a igualdade do século dezenove, tem-se aquela profunda narrativa 
que acompanha textos importantes como o do preâmbulo da Carta das Nações Unidas ${ }^{7}$ e, sobretudo, da Declaração Universal dos Direitos Humanos de dezembro de 1948.

Com esta declaração tem-se a possibilidade da consagração do fim da barbárie e violência das guerras e de seus holocaustos. Ademais, pode-se falar de uma consciência de participar de uma comunidade humana como reconhecimento da dignidade inerente a todos os membros da família humana e de seus direitos, os quais constituem o fundamento da liberdade, da justiça e da paz no mundo. A Declaração se apresenta como uma condição de possibilidade, como um desafio, porém não basta estar declarada a dignidade é preciso que a comunidade humana a torne efetiva.

O "constituir" é explícito. A barbárie afeta os cidadãos no momento em que a dignidade é violada". Não por acaso o artigo $1^{\circ}$ da declaração trata da inviolabilidade da dignidade das pessoas, aproximando-se de maneira evidente ao "dever de se comportar no espírito de fraternidade".

A dignidade tem uma profunda ligação com a comunidade humana bem como com a negação dos poderes selvagens que despertam barbárie e aberrações. Com a dignidade temos mais do que o direito de não nos vermos em situação de sofrimento e humilhação, colocando-se em jogo "o direito a reconhecer-se como homem", o reflexo de não se reconhecer não é sem significado.

A consciência social, cultural e, também, "política" da dignidade repousa sobre a tomada de consciência de que "ser homem" e "ter humanidade" não necessariamente coincidem, assim como existe um abismo entre ser irmão e ser fraterno. Decerto é na humanidade que se produz a barbárie, mas é sempre apenas na humanidade que os remédios para a barbárie podem ser encontrados.

Assim, o direito à dignidade coloca em jogo este tema decisivo: é dever de todos reconhecer e tutelar a dignidade de cada um. Não é por acaso que se nos voltarmos para a esfera pública e, em particular, àqueles poderes públicos que somente estarão legitimados se perseguirem o objetivo do reconhecimento e da tutela da dignidade de cada ser vivente (não somente cidadão). Por exemplo, o art. $1^{\circ}$ da Constituição alemã de 1949, não por acaso afirma que "a dignidade do homem é intangível", acrescentando que "respeitar e protegê-la é obrigação de cada poder estatal". Não menos importante que a "Grundgesetz" alemã é a previsão da Constituição italiana, que no art.3ํㅏㄹefere-se à

\footnotetext{
7 Preâmbulo - Nós, os povos das nações unidas, resolvidos a preservar as gerações vindouras do flagelo da guerra, que por duas vezes, no espaço da nossa vida, trouxe sofrimentos indizíveis à humanidade, e a reafirmar a fé nos direitos fundamentais do homem, na dignidade e no valor do ser humano, na igualdade de direito dos homens e das mulheres, assim como das nações grandes e pequenas, e a estabelecer condições sob as quais a justiça e o respeito às obrigações decorrentes de tratados e de outras fontes do direito internacional possam ser mantidos, e a promover o progresso social e melhores condições de vida dentro de uma liberdade ampla. E para tais fins, praticar a tolerância e viver em paz, uns com os outros, como bons vizinhos, e unir as nossas forças para manter a paz e a segurança internacionais, e a garantir, pela aceitação de princípios e a instituição dos métodos, que a força armada não será usada a não ser no interesse comum, a empregar um mecanismo internacional para promover o progresso econômico e social de todos os povos. Resolvemos conjugar nossos esforços para a consecução desses objetivos. Em vista disso, nossos respectivos Governos, por intermédio de representantes reunidos na cidade de São Francisco, depois de exibirem seus plenos poderes, que foram achados em boa e devida forma, concordaram com a presente Carta das Nações Unidas e estabelecem, por meio dela, uma organização internacional que será conhecida pelo nome de Nações Unidas. Disponível em https://nacoesunidas.org/carta/. Acesso em 27 out. 2017.
} 
igual dignidade social de cada indivíduo, obrigando a República a remover os obstáculos que possam obstaculizá-la ${ }^{8}$. Sua aplicação concreta, está, de fato, prevista no art. 36 que garante, através da retribuição dos trabalhadores, uma existência livre e digna.

No contexto dos direitos fundamentais das Constituições podemos encontrar um perfil complexo da definição jurídico-política da dignidade humana, da autodeterminação e da proibição de discriminações à liberdade e à igualdade.

Reconhecimento e tutela são, então, as expressões usadas pelos textos jurídicos; não por acaso, a tutela está junto da forma "declarativa" de reconhecimento. Reconhecer-se indica uma dimensão já existente na natureza do homem, no fato de existir, de fazer parte de uma comunidade humana que o direito se limita a registrar de modo formal. A tutela, ao contrario, envolve a violação e o compromisso dos poderes para reconstituir seu conteúdo. Na verdade, na ideia jurídica de reconhecimento e de tutela, que se referem a campos linguísticos diversos, convergem todos os grandes dilemas das disputas filosóficas sobre a dignidade. O imperativo é a síntese que depois será assumida pelas Cortes, como está acontecendo, no preenchimento do conteúdo.

Antes de mais nada, dissolvem-se as dúvidas se é a dignidade o fundamento dos direitos humanos, ou, ao contrário, se os direitos humanos são o fundamento da dignidade. Sobretudo na ideia de direito a dignidade se condensam todas as variações semânticas que a têm acompanhado: ela foi indicada como virtude a ser aprendida, como mérito e privilégio adquirido, como trabalho ou como resposta a um dever, como qualidade intrínseca ou como legitimação para aquisição de direitos.

A dignidade do homem é a reivindicação de reconhecer-se como homem, em todos os casos, contra os poderes concretos que a viola constantemente. De fato, isso muda em referências empíricas mas permanece igual na ideia de um projeto de comunidade humana em que os menos privilegiados têm direito ao reconhecimento e à proteção de igual dignidade e, portanto, compartilham o mesmo privilégio da "família humana" da humanidade. Os menos privilegiados são aqueles que, em casos históricos concretos, encontram-se na condição que a violência e a humilhação dos poderes selvagens infligem a "vida nua" das pessoas, como seres viventes e não apenas simples "cidadãos".

\section{COMPREENSÃO JURÍDICA DA DIGNIDADE HUMANA E A RELAÇÃO COM A FRATERNIDADE}

$\mathrm{Na}$ introdução ao pensamento filosófico Karl Jaspers (2005, p. 53) ressalta que "a dignidade do homem reside no fato de ele ser indefinível. O homem é como é, porque reconhece essa dignidade em si mesmo e nos outros homens". Esse fundamento antropocêntrico da dignidade traduz sua relevância e indica o caminho para a compreensão jurídica da dignidade.

\footnotetext{
${ }^{8}$ Art. 3o da Constituição Italiana - "Todos os cidadãos têm a mesma dignidade social e são iguais perante a lei, sem discriminação de sexo, de raça, de língua, de religião, de opiniões políticas, de condições pessoais e sociais. Cabe à República remover os obstáculos de ordem social e econômica que, limitando de facto a liberdade e a igualdade dos cidadãos, impedem o pleno desenvolvimento da pessoa humana e a efectiva participação de todos os trabalhadores na organização política, econômica e social do País".
} 
No entanto, não é difícil constatar que a dignidade comporta várias dimensões, o que dificulta sua compreensão jurídica. A dimensão teológico-cristã, por exemplo, constituiu um embrião para a garantia da dignidade ao considerar que todos os homens são criados, igualmente, à imagem e semelhança de Deus, dotados, portanto, de igual dignidade. Na questão 29 de sua suma teológica, ao tratar das pessoas divinas, Santo Tomás de Aquino (2001) define pessoa como ser dotado de dignidade, ressaltando que essa dignidade provém da correspondente dignidade de natureza divina.

Apesar da relevância de sentido, o enraizamento teológico da dignidade não é adequado a um Estado secular neutro, não podendo servir de único alicerce para sua fundamentação jurídica.

Por ser qualidade inerente a todo ser humano, a dignidade revela também dimensão ontológica. Referida dimensão teve seu esboço inicial com Giovanni Pico Della Mirandola (2008) na obra Discurso Sobre a Dignidade do Homem, que sublinhou a importância da busca pelo conhecimento como fator importante para autodeterminação do indivíduo, e, articulada com a ética e a metafísica constituem a substância da dignidade. Ao traçar uma visão antropocêntrica do mundo e detectar na dignidade do homem a articulação entre liberdade (autodeterminação), responsabilidade moral (ética) e conhecimento da natureza (metafísica) a doutrina humanista do Conde de Concordia não conseguiu dessacralizar a dignidade, mantendo a forte raiz teológica.

É na evolução do pensamento jusnaturalista que a dignidade humana assume um aspecto mais racional, fundamentando-se na igualdade dos homens de forma livre ${ }^{9}$. Mas é verdadeiramente com o processo de secularização, que a dignidade se consagra de maneira mais semelhante à compreensão contemporânea.

Assim, no século XVIII, a filosofia prática kantiana destacou o dever de respeito à dignidade do outro, ao vedar a instrumentalização humana ${ }^{10}$, conferindo base para o complicado processo de racionalização e laicização almejado pelo lluminismo.

Kant (2004) sustenta que as pessoas são seres racionais e que sua existência depende da natureza. Como essa já os condicionou à qualidade de fins em si mesmos, esses não podem ser empregados como meios para satisfação de outrem, devendo-se, assim, garantir o respeito a sua dignidade. Na Fundamentação da Metafísica dos Costumes, Kant atribui a autonomia da vontade à capacidade de autodeterminação como inerente aos seres racionais. Em decorrência da capacidade de ação autodeterminada, orientada pela razão, o indivíduo tem o dever de respeitar a dignidade do outro e a própria e o direito de que sua dignidade seja respeitada, revelando um imperativo prático motivador de um estado jurídico.

Na percepção de Kurt Seelman (2009), para o sistema ético kantiano, a dignidade mais do que um conceito em si, constitui-se em um dever de respeito. Esse respeitar estaria no liame entre

\footnotetext{
${ }^{9}$ No entender de Ingo Sarlet (2011, pp. 38-39), Samuel Pufendorf, por exemplo, credita à dignidade a base que sustenta a liberdade e a igualdade entre os homens. Ela se constituiria na liberdade moral: respeitar a liberdade de opção que o ser humano tem e que faz através do seu entendimento e razão.

${ }^{10}$ Como sustenta Kant $(2004$, p.65) "no reino dos fins tudo tem ou um preço ou uma dignidade. Quando uma coisa tem um preço, pode pôr-se em vez dela qualquer outra como equivalente; mas quando uma coisa está acima de todo o preço, e, portanto, não permite equivalente, então tem ela dignidade. (...) Esta apreciação dá pois a conhecer como dignidade o valor de uma tal disposição de espírito e põe-na infinitamente acima de todo preço. Nunca ela poderia ser posta em cálculo ou confronto com qualquer coisa que tivesse um preço, sem de qualquer modo ferir sua santidade".
}

Revista do Direito [ISSN 1982-9957]. Santa Cruz do Sul, v. 3, n. 53, p. 92-103, set./dez. 2017. https://online.unisc.br/seer/index.php/direito/index 
um dever jurídico e um dever de virtude. No primeiro sentido, assemelha-se a uma conduta negativa: a ninguém lesar seus direitos. No segundo, vincula-se a uma conduta positiva: a assistência positiva do imperativo de amor ao próximo.

Observa-se na tradição kantiana um entrelaçamento entre liberdade e dignidade. Conforme pontua Béatrice Maurer (2013, p.132), "a dignidade não pode ser compreendida sem a liberdade, nem a liberdade sem a dignidade".

Além da forte ligação com a liberdade, a dignidade ganha sentido na intersubjetividade e no complexo processo de reconhecimento hegeliano, aproximando-se do princípio da fraternidade. Partindo de premissas kantianas, Hegel aponta a necessidade de respeito recíproco através do reconhecimento do outro como pessoa ${ }^{11}$. Todavia, diferentemente da linha kantiana, este dever de respeito é um imperativo jurídico e não um dever de virtude, sendo a dignidade produto do reconhecimento recíproco e objeto de proteção jurídica. A esfera hegeliana da dignidade revela que os indivíduos têm dignidade no reconhecimento como iguais, isto é, como sujeitos de direitos e deveres num contexto relacional (SELLMAN, 2013, p.118). Essa perspectiva comunicativa e relacional destaca a dignidade como "categoria da co-humanidade de cada indivíduo" (SARLET, 2013) e indica limitação da liberdade individual no relacionamento em comunidade por exigir uma liberdade com responsabilidade ${ }^{12}$.

A condição ontológica do ser humano faz com que a dignidade possua também um sentido cultural, por ser produzida "necessariamente em vista de outro que não ela mesma, em vista da totalidade dos fenômenos da cultura em que ela surge" (ABED AL-JABRI, 1999, p.31). Por certo, a dignidade manifesta- se de forma diferenciada a depender da conjuntura em que está inserida e da especificidade cultural de cada comunidade. Na trilha de Ricardo Maurício Freire Soares, "a delimitação do significado ético-jurídico de que o ser humano é um fim em si mesmo deve ser buscada em cada contexto histórico-cultural, no plano real de afirmação dos valores que integram a experiência concreta"13. Desse modo, refuta-se uma compreensão unívoca da dignidade, que deverá ser formulada casuisticamente de acordo com a realidade em que está imersa ou a partir de um diálogo intercultural.

O discurso jurídico da dignidade humana no seu caráter contemporâneo está involucrado na concepção de mundo predisposto à reorganização das estruturas sociais e políticas perante os alicerces de uma tradição que, ao ser repensada constantemente na identidade individual e coletiva,

\footnotetext{
${ }^{11}$ No processo de reconhecimento deve-se ter cuidado com o que Hegel denominou "dialética do senhor e do escravo", metáfora que pode ser utilizada para explicar o reconhecimento do outro através da força e do sentimento de propriedade. Sem dúvida o reconhecimento alcançado pela dominação perde qualquer valor e não se relaciona com o princípio da fraternidade. Nesse sentido, Menelick de Carvalho Netto (2003, p. 154) destaca que "somente reconhecendo os outros como iguais, como pessoas iguais a mim, posso reconhecer a mim mesmo como sujeito de um processo de vida individual que só se dá na interação complexa da vida coletiva e aprender com esse processo, tornando-me sujeito portador de uma identidade própria".

12 José Casalta Nabais (2007) defende que a liberdade deve estar conjugada à responsabilidade na teoria dos direitos e deveres fundamentais. É oportuno registrar que a obra tem como parâmetro a Constituição portuguesa de 1976 e posteriores reformas, de modo que deve ser contextualizada à realidade da Constituição brasileira.

${ }^{13}$ Ricardo Maurício Freire Soares (2010, p.142-143) anota ainda que "a dignidade do outro estará, portanto, sempre vinculada ao reconhecimento recíproco de que o ser humano não pode ser degradado ou coisificado, o que constitui a base da convivência humana em sociedade".
}

Revista do Direito [ISSN 1982-9957]. Santa Cruz do Sul, v. 3, n. 53, p. 92-103, set./dez. 2017. https://online.unisc.br/seer/index.php/direito/index 
possibilita vivenciar novos modelos sociais. Necessário destacar que a compreensão da identidade do sujeito não significa uma habilidade superficial no manejo da convivência, mas a capacidade de apreender a verdade do outro e estabelecer formas significativas de interação em prol de uma realização construtiva dos direitos humanos e fundamentais. A identidade coletiva, por sua vez, repousa nas expressões da cultura em que é possível delinear as marcas da comunidade e perceber padrões de ordem social valorativa.

Esse teor da dignidade acompanha o modelo constitucional contemporâneo e a experiência das instituições políticas, consagrando o respeito à diversidade num contexto multicultural ${ }^{14}$. Nesta linha de entendimento parece situar-se o pensamento de J. J. Gomes Canotilho (2003, p.225-226) ao sustentar que a dignidade humana "exprime a abertura da República à ideia de comunidade constitucional inclusiva pautada pelo multiculturalismo multividencial, religioso ou filosófico".

Essa breve abordagem das dimensões da dignidade permite identificar uma semelhança pragmática (não terminológica) com a fraternidade. O reconhecimento da dignidade humana torna necessária a fraternidade uma vez que "a dignidade do outro me obriga à fraternidade" (MAURER, 2013, p. 140). Por ser condição humana interior, a dignidade exterioriza- se através da fraternidade, no processo de reconhecimento da dignidade do outro.

Seguindo o pensamento de Ricardo Hasson Sayeg e Wagner Balera (2011, p.119):

[...] a dignidade da pessoa entremostra-se presente no adensamento entre liberdade, igualdade e fraternidade, emergindo objetivamente do respectivo equilíbrio reflexivo. Explica-se: de que vale a dignidade da pessoa humana sem liberdade? Sem igualdade? Sem fraternidade? Sem liberdade haverá a tirania da igualdade. Sem igualdade, a tirania da liberdade. E, sem fraternidade, liberdade e igualdade são incompatíveis.

Para além disso, dignidade e fraternidade alcançam, numa perspectiva transversal, a "racionalidade ecológica", configurada no âmbito da diversidade social da experiência vivida. Ao propor o conceito de racionalidade ecológica, Carlos Alberto Molinaro (2006) destaca que é "todo o exercício da razão que privilegia as formas impuras e periféricas do pensamento, desde formas argumentativas, empíricas, e procedimentos indutivos para a indagação e compreensão da realidade socioambiental".

A transmissão da fraternidade pela via da cultura é transportada pela condição democrática na medida em que, ao experimentar a vivência autêntica da fraternidade, se ocupa também da dignidade, fazendo com que ela assuma aspecto dialético e plural.

Decerto, há, no princípio da fraternidade, a ideia originária da dignidade uma vez que a fraternidade está integrada ao reconhecimento da condição humana, de maneira que, ao praticar o ato fraterno, também se pratica um ato digno. Diante do conteúdo jurídico da fraternidade, os intérpretes do direito devem atualizar o sentido de comunidade política e democrática integrado ao aspecto específico da dignidade humana no viés constitucional.

\footnotetext{
${ }^{14}$ Entende-se por multiculturalismo a necessidade de reconhecimento e respeito às diferenças culturais, de modo a viabilizar uma convivência pacífica e fraterna. Nesse sentido conferir TAYLOR (1999);
}

Revista do Direito [ISSN 1982-9957]. Santa Cruz do Sul, v. 3, n. 53, p. 92-103, set./dez. 2017. https://online.unisc.br/seer/index.php/direito/index 
A ordem constitucional fraterna ocupa um processo sociojurídico de adequação de sentido da dignidade, dado que a dignidade humana, enquanto experiência originária e fundante ${ }^{15}$, é elemento direcionador e estruturador da fraternidade. Deste modo, torna-se perceptível que a referência à fraternidade requer um sentido de autenticidade no reconhecimento da condição humana.

Não bastasse isso, a fraternidade expande o imaginário da tradição moderna individualista ao direcionar o aspecto intersubjetivo da consciência fraterna na esfera do reconhecimento social. Assim sendo, a consagração jurídica da fraternidade numa sociedade plural e multidimensional intensifica o respeito pela dignidade humana assim como o conteúdo jurídico da dignidade repercute na razão fraterna ao direcionar o movimento dialético em meio às consciências individuais e sociais.

A intuição fundamental do valor da dignidade como critério de escolha jurídica define a figura constitucional da fraternidade já que o ato de reconhecimento incorpora o critério de valor humano. Como pontua Edmilson Menezes, "a luta pelo reconhecimento nas relações intersubjetivas é o aspecto fundante da vida em comunidade" (MENEZES, 2000, p. 84) inserido no elemento da cultura.

O movimento fraterno na teoria do direito contemporâneo ocorre de maneira diferenciada da tradição iluminista dado que a consciência da fraternidade se coaduna com a consciência da identidade coletiva, rompendo processos de indiferença social típicos do Estado liberal, preservando a unidade primordial da dignidade humana ${ }^{16}$. Sendo assim, a experiência da dignidade tal qual a da fraternidade, ao se inserirem no movimento intersubjetivo das relações sociais, equaciona desafios na efetivação de direitos humanos e fundamentais.

A realização dos direitos humanos reside num espaço multidimensional e multicultural em meio a conflitos de interesses e encontram no marco constitucional da dignidade e fraternidade um eixo aglutinador de experiências coletivas numa perspectiva mediadora e não numa supressão superficial dos conflitos sociais, enfrentando, deste modo, os impasses da contemporaneidade (BARRENECHE, 2009, p.99).

A fraternidade encaminha-se, portanto, para a realização de um processo mediador construtivo da interação comunicativa, agindo no enfrentamento dos conflitos sociais e culturais. De modo geral, a autenticidade da razão fraterna vem a partir da consciência individual e coletiva como condição essencial para a aplicação da dignidade humana. De fato, a dignidade exige a autenticidade do sujeito que conhece e reconhece a relação com o outro e, nessa condição, apreende o sistema das tradições jurídicas e políticas que permeiam as estruturas sociais.

Pode-se afirmar, ainda, que a dimensão ético-jurídica da fraternidade produz uma reconstrução hermenêutica, fazendo com que as perspectivas e valorações jurídicas apresentem- se num universo de experiências que possibilitem o fortalecimento das instituições através da

\footnotetext{
${ }^{15}$ Nas lições de Carlos Ayres Britto (2007, p.27) “o princípio jurídico da dignidade da pessoa humana decola do pressuposto de que todo ser humano é um microcosmo. Um universo em si mesmo. Um ser absolutametne único, na medida em que, se é parte de um todo, é também um todo à parte; isto é, se toda pessoa natural é parte de algo (o corpo social), é ao mesmo tempo um algo a parte. A exibir na lapela da própria alma o bóton de uma originalidade que ao Direito só compete reconhecer até para se impor como expressão, da vida comum civilizada".

${ }^{16}$ Nesse sentido, Miriam Coutinho Alves de Farias (2014, p.105) ressalta que "Na medida em que reconheço em mim a dignidade e estendo este reconhecimento à vida coletiva dou abertura para a integração com o outro. $\mathrm{E}$ quando se projeta direitos de caráter fundamental e suas garantias se realiza o deslocamento de um olhar individualista para um olhar sociocultural."
}

Revista do Direito [ISSN 1982-9957]. Santa Cruz do Sul, v. 3, n. 53, p. 92-103, set./dez. 2017. https://online.unisc.br/seer/index.php/direito/index 
interdisciplinaridade e transversalidade como um processo que permite reestruturar as situações de conflito.

A fraternidade almeja a paz apreendida como síntese elaborativa das condições de desarmonia nas esferas de comunicação entre os indivíduos, grupos sociais ou instituições. O tempo presente será assim um tempo sensível (KRISTEVA, 1994) que, a partir da fraternidade, ressignifica a noção de dignidade no inconsciente coletivo.

A dignidade como unidade estruturadora da fraternidade tem, a partir do aspecto dialógico, uma função integrativa e fecunda na hermenêutica constitucional, acolhendo, a partir do reconhecimento da condição humana a perspectiva de ser um pensamento aglutinador das relações entre os indivíduos (ALVES, 2014, p. 100).

Certamente, o princípio da fraternidade é direcionador de um projeto político-democrático enquanto norma preceptiva que considera a dignidade humana como marco da liberdade, igualdade e fraternidade e limite de sentido. Ademais, a fraternidade está inserida num conceito de justiça plural, pois estabelece diálogos interculturais transitando nas articulações entre direitos e deveres fundamentais, que se comungam numa visão tridimensional do direito (REALE, 2002), encontrando sentido na concepção de vida digna.

\section{CONSIDERAÇÕES FINAIS}

Neste artigo colocamos vários "contratempos", sendo o principal a relação entre dignidade humana e fraternidade. Questionamos como na tradução do direito em conceitos deixou-se de lado a fraternidade e seus correlatos. Hoje a fraternidade não se apresenta apenas como um vago dispositivo de solidariedade entre nações, uma vez que rompe com o código amigo/inimigo e com as certezas do bom e do justo, propondo a necessidade de transferir o modelo da amizade à dimensão da fraternidade. Transformar a fraternidade em código e fazê-la regra, como todos os paradoxos, como contratempo, desvela a contemporaneidade não contemporânea.

O Direito Fraterno recoloca o lugar de auto-responsabilização, desde que liberada da rivalidade do modelo "irmãos inimigos". A fraternidade das constituições reabre o jogo da amizade política, mas não elimina seus paradoxos.

Não é possível falar em fraternidade sem aprofundar o tema da dignidade, da comunidade, da humanidade do humano; foi o que abordamos neste artigo utilizando os pressupostos norteadores do direito fraterno: compartilhar, esta foi e é a melhor lição que nos ensina Eligio Resta.

\section{REFERÊNCIAS}

ABED AL-JABRI, Mohammed. Introdução à crítica da razão árabe. Trad. Roberto leal Ferreira. São Paulo: Editora Unesp, 1999.

ALVES, Miriam Coutinho de Farias. O paradigma de gênero da ciência jurídica: horizontes do feminismo na concretização dos direitos fundamentais da mulher. Tese de doutorado em direito. Programa de pós-graduação da UFBA. Faculdade de direito. Universidade Federal da Bahia, 2014. 
AQUINO, Santo Tomás. Suma de teologia. Trad. José Martorell Capó. 4 ed. Madrid: Biblioteca de Autores Cristianos, 2001.

BAGGIO, Antonio Maria (Org.). O Princípio Esquecido/1: A fraternidade na reflexão atual das ciências políticas. Traduções Durval Cordas, Iolanda Gaspar; José Maria de Almeida. Vargem Grande Paulista - SP: Cidade Nova, 2008.

O Princípio Esquecido/2: Exigências, recursos e definições da fraternidade na política. Traduções Durval Cordas, Luciano Menezes Reis. Vargem Grande Paulista - SP: Cidade Nova, 2009.

BARRENECHE, Osvaldo. La idea de fraternidad en el congresso de Panamáde 1826 y los intentos de integración política de la America Latina luego su independência. In: BAGGIO, Antonio M. La fraternidad en perspectiva politica: exigências, recursos, deficiones del principio olvidado.1.ed. Buenos Aires: Ciudad Nueva, 2009.

BRITTO, Carlos Ayres. O humanismo como categoria constitucional. Belo Horizonte: Editora Fórum, 2007.

CANOTILHO, José Joaquim Gomes. Direito Constitucional e Teoria da Constituição. 7. ed. Coimbra: Almedina, 2003.

CARVALHO NETTO, Menelick de. A Hermenêutica Constitucional e os desafios postos aos Direitos Constitucionais. In: José Adécio Leite Sampaio. (Org.). Jurisdição Constitucional e Direitos Fundamentais. Belo Horizonte: Del Rey, 2003, p. 141-163.

CUNHA, Paulo Ferreira da. Direito Fraterno Humanista. Rio de Janeiro: LMJ Mundo Jurídico, 2017.

JASPERS, Karl. Introdução ao pensamento filosófico. Tradução: Leônidas Hegenberg e Octanny Silveira da Mota. São Paulo: Cultrix, 2005.

KANT, Immanuel. Fundamentação da metafísica dos costumes e outros escritos. São Paulo: Martin Claret, 2004.

KRISTEVA, Julia. Le temps sensible - Proust et l'expérience littéraire. Paris: Gallimard, 1994.

MAURER, Béatrice. Notas sobre o respeito da dignidade da pessoa humana... ou pequena fuga incompleta em torno de um tema central. In: Dimensões da Dignidade: ensaios de Filosofia do Direito e Direito Constitucional. 2 ed. Porto Alegre: Livraria do Advogado Editora, 2013.

MENEZES, Edmilson. História e esperança em Kant. São Cristovão: Editora UFS, Fundação Oviêdo Teixeira, 2000

MIRANDOLA, Giovanni Pico Della. Discurso sobre a dignidade do homem. Edição bilíngüe, Lisboa: Edições 70. LDA, 2008.

MOLINARO, Carlos Alberto. Racionalidade Ecológica e Estado Socioambiental e Democrático de Direito. Dissertação de mestrado. Pontifícia Universidade Católica do Rio Grande do Sul. 2006. Disponível em http://tede2.pucrs.br/tede2/bitstream/tede/4093/1/381018.pdf. Acesso em 28 de outubro de 2017.

NABAIS, Casalta. Por uma liberdade com responsabilidade: estudos sobre direitos e deveres fundamentais. Coimbra: Coimbra Editora, 2007.

REALE, Miguel. Filosofia do Direito. 19 ed. 3 tir. São Paulo: Saraiva, 2002.

RESTA, Eligio. Per un Diritto Fraterno. In: FINELLI, R. (et. al.). Globalizzazione e Diritti Futuri. Roma: Manif, 2004a. 
. O Direito Fraterno. Tradução e coordenação de Sandra Regina Martini Vial. Santa Cruz do Sul: EDUNISC, 2004b.

The quest for fraternal rights. In Dasi, Gerardo Filiberto(org.).The economics of the noble path. Fraternal rights, the convivial society, fair shares for all. Rimini: La Moderna, 2003.

II Diritto fraterno. 1. ed. Bari: Laterza, 2002.

El derecho fraterno, in Anales de la Catedra Francisco Suarez, 1994.

La comunidad inconfesable y el derecho fraterno, in Identidades comunitaria y democrazia, a cura di H. S. Gorski, Trotta, Madrid, 2000.

SAYEG, Ricardo Hasson e BALERA, Wagner. O Capitalismo Humanista: Filosofia Humanista de Direito Econômico. POD. Petrópolis: KBR, 2011.

SARLET, Ingo Wolfgang. Dignidade da pessoa humana e direitos fundamentais na Constituição Federal de 1988. Porto Alegre: Livraria do Advogado, 2011.

SARLET, Ingo Wolfgang. As dimensões da dignidade da pessoa humana: construindo uma compreensão jurídico-constitucional necessária e possível. In: Dimensões da Dignidade: ensaios de Filosofia do Direito e Direito Constitucional. 2 ed. Porto Alegre: Livraria do Advogado Editora, 2013.

SEELMAN, Kurt. Pessoa e dignidade da pessoa humana na filosofia de Hegel. In: Dimensões da Dignidade: ensaios de Filosofia do Direito e Direito Constitucional. 2 ed. Porto Alegre: Livraria do Advogado Editora, 2013.

SOARES, Ricardo Maurício Freire. O Princípio Constitucional da Dignidade da pessoa humana. 1. ed. São Paulo: Saraiva, 2010.

TAYLOR, Charles. A política de reconhecimento. In: TAYLOR, Charles (org). Multiculturalismo: examinando a política de reconhecimento. Lisboa: Instituto Piaget, 1998; SEMPRINI, Andrea. Multiculturalismo. Bauru: EDUSC, 1999.

\section{COMO CITAR ESSE DOCUMENTO:}

MARTINI, Sandra. Direito e fraternidade: a dignidade humana como fundamento. Revista do Direito, Santa Cruz do Sul, v. 3, n. 53, dez. 2017. ISSN 1982-9957. Disponível em: <https://online.unisc.br/seer/index.php/direito/article/view/11364>. Acesso em: doi:http://dx.doi.org/10.17058/rdunisc.v3i53.11364. 